\title{
Hammock and nesting in preterm infants: randomized controlled trial
}

\author{
Rede de descanso e ninho em prematuros: ensaio clínico randomizado \\ Hamaca de descanso y nido en prematuros: ensayo clínico aleatorizado
}

\section{Kassandra Silva Falcão Costa' \\ ORCID: 0000-0002-6456-2315 \\ Danielle da Silva Fernandes' ORCID: 0000-0002-3894-7350}

Rayanne Augusta Parente Paula' ORCID: 0000-0002-9048-420X

Laíse Escalianti Del Alamo Guarda' ORCID: 0000-0002-2084-0117

Mariana Firmino Daré"

ORCID: 0000-0002-1782-559X

Thaíla Côrrea Castral I"' ORCID: 0000-0003-1319-0483

Laiane Medeiros Ribeiro ORCID: 0000-0002-5041-8283

'Universidade de Brasília. Brasília, Distrito Federal, Brazil. "Universidade de São Paulo. Ribeirão Preto, São Paulo, Brazil. "'Universidade Federal de Goiás. Goiânia, Goiás, Brazil.

How to cite this article: Costa KSF, Fernandes DS, Paula RAP, Guarda LEDA Daré MF, Castral TC, et al. Hammock and nesting in preterm infants: randomized controlled trial Rev Bras Enferm. 2019;72(Suppl 3):96-102. doi: http://dx.doi.org/10.1590/0034-7167-2018-0099

Corresponding Author:

Kassandra Silva Falcão Costa

E-mail: kassandrafcosta@gmail.com

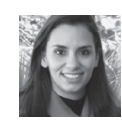

Submission: 03-21-2018

Approval: 07-12-2018

\section{ABSTRACT}

Objective: To compare the physiological variables and the sleep-wake pattern presented by preterm in nesting and hammock positions after diaper change. Method: This is a crossover randomized controlled trial. It was conducted with 20 preterm infants who, after diaper change, were placed in nests or hammocks. These preterm infants were evaluated for physiological variables (heart rate and oxygen saturation) and behavioral variables (sleep and wakefulness). Results: There was no statistically significant difference in the studied variables between nesting and hammock positions. However, regarding the categorical variable sleep, the comparison between the research phases for the hammock position showed differences between the baseline phase and the immediate recovery $(p=0.00)$, baseline and late recovery $(p=0.00)$, response and immediate recovery $(p=0.00)$, response and late recovery $(p=0.00)$. Conclusion: No differences were identified between the nest and the hammock; however, the use of the hammock favored the sleep of preterm infants compared to its non-use.

Descriptors: Patient Comfort; Premature; Patient Positioning; Sleep; Neonatal Intensive Care Units.

\section{RESUMO}

Objetivo: Comparar as variáveis fisiológicas e o padrão de sono-vigília apresentados por prematuros, quando colocados em rede e em ninho, após a troca de fraldas. Método: Tratase de um Ensaio Clínico Randomizado do tipo cross-over, realizado com 20 prematuros que, após a troca de fraldas, foram posicionados em redes de descanso e ninho. Esses prematuros foram avaliados quanto às variáveis fisiológicas (frequência cardíaca e saturação de oxigênio) e variável comportamental (sono e vigília). Resultados: Não houve diferença estatisticamente significativa entre as condições ninho e rede quanto às variáveis estudadas. Entretanto, quanto à variável categórica sono, nas comparações entre as fases da pesquisa para a condição rede, houve diferenças entre fase basal e recuperação imediata $(p=0,00)$, basal e recuperação tardia $(p=0,00)$, resposta e recuperação imediata $(p=0,00)$, resposta $e$ recuperação tardia $(p=0,00)$. Conclusão: Não se identificaram diferenças entre rede e ninho, entretanto, o uso da rede favoreceu o sono de prematuros comparado ao seu não uso. Descritores: Conforto do Paciente; Prematuro; Posicionamento do Paciente; Sono; Unidade de Terapia Intensiva Neonatal.

\section{RESUMEN}

Objetivo: comparar las variables fisiológicas y el patrón de sueño y vigilia presentados por prematuros, cuando ellos son puestos en hamaca y en nido, después del cambio de pañales. Método: Se trata de un ensayo clínico aleatorizado del tipo crossover. Realizado con 20 prematuros que, tras el cambio de pañales, fueron colocados en hamacas de descanso y nido. Estos prematuros fueron evaluados en cuanto a las variables fisiológicas (frecuencia cardíaca y saturación de oxígeno) y variable conductual (sueño y vigilia). Resultados: No hubo diferencia estadísticamente significativa entre las condiciones nido y hamaca en cuanto a las variables estudiadas. Sin embargo, en cuanto a la variable categórica sueño, en las comparaciones entre las fases de la investigación para la condición hamaca, hubo diferencias entre fase basal y recuperación inmediata $(p=0,00)$, basal y recuperación tardía $(p=0,00)$, respuesta y recuperación inmediata $(p=0,00)$, respuesta y recuperación tardía $(p=0,00)$. Conclusión: No se identificaron diferencias entre hamaca y nido, sin embargo, el uso de la hamaca favoreció el sueño de prematuros en comparación a su no utilización. Descriptores: Comodidad del Paciente; Prematuro; Posicionamiento del Paciente; Sueño; Unidades de Cuidado Intensivo Neonatal. 


\section{INTRODUCTION}

During their stay in the Neonatal Intensive Care Unit (NICU), Preterm Infants (PI) receive different stimuli, such as exposure to light, intense noise and stressful and painful interventions. These stimuli may interfere with the cognitive and behavioral development of the preterm infant ${ }^{(1-2)}$, and are associated with changes in physiological parameters, such as Heart Rate (HR), Oxygen Saturation $\left(\mathrm{SpO}_{2}\right)$, salivary cortisol, and behavioral parameters, such as variations in sleep and wakefulness, facial mimicry, crying ${ }^{(3-5)}$.

Studies on the effects of diaper change in PI showed lower $\mathrm{SpO}_{2}$, higher $\mathrm{HR}^{(6)}$, changes in skin conductance peaks (Skin Conductance Algesimeter) ${ }^{(7)}$, higher levels of salivary cortisol, and increased scores on pain scale ${ }^{(6-8)}$ during this procedure. Therefore, studies have demonstrated that diaper change can be a stressful event during routine care of preterm infants ${ }^{(6-8)}$.

Considering that diaper changes occur on average eight times a day, along with other painful procedures for diagnostic and therapeutic purposes, interventions that minimize stressrelated brain damage among preterm infants become necessary. Positioning is one of the most studied interventions to provide comfort and reduce stress among these patients ${ }^{(9-11)}$. In addition, therapeutic positioning is an important tool to improve sleep in premature infants ${ }^{(12-13)}$.

A tool used to promote a proper positioning of the preterm infant is the nest, which is a cloth rolled in an " $\mathrm{U}$ " or "O" shape, which supports the baby from head to toe in a format that resembles the maternal uterus. This method provides postural support with reduction of energy expenditure and alignment of the head and trunk, and promotes flexed postures, which contribute to the neurobehavioral development of preterm infants ${ }^{(11,14)}$.

A crossover study evaluated the effects of the supportive nest on behavioral and physiological variables of preterm infants while undergoing a diaper change, comparing the results with nonnested babies. The results showed higher HR $(p=0.012)$ and lower distress scores, facial mimicry and facial pain scores $(<0.0001)$ in the group using the nest, through the NFCS (Neonatal Facial Coding System) ${ }^{(11)}$.

Another innovative way of positioning the preterm or full term infant is the hammock, a technique that consists in positioning the baby in hammocks inside the incubator and/or heated crib during hospitalization ${ }^{(15-16)}$. This positioning has been widely used in the Northeast region of Brazil; however, there are few clinical studies that evaluate its use as a comfort strategy.

The hammock positioning simulates the uterine position due to its flexed and aligned nature, keeps hands close to the mouth, and provides smooth and continuous movements. This technique can help preterm infants to overcome the effects of lack of containment and extrauterine forces and stimulates reflexes and the vestibular system (balance, protection and sensory integration), factors impaired by immaturity ${ }^{(15,17)}$.

Given the prolonged hospitalization of preterm infants in neonatal units and the deleterious effects of repetitive painful and stressful stimuli for premature infants, the objective of this study was to compare the physiological variables and the sleep-wake pattern presented by preterm infants in nesting or hammock positions after diaper change.
The hypothesis of the study is that, after diaper change, the hammock position is associated with better results regarding physiological parameters (heart rate and oxygen saturation) and behavioral parameters (sleeping and wakefulness) of preterm infants, when compared to nesting.

\section{OBJECTIVE}

To compare the physiological variables and the sleep-wake pattern presented by preterm infants in nesting or hammock positions after diaper change.

\section{METHOD}

\section{Ethical Aspects}

The study followed ethical principles for research according to Resolution 466 of 2012. It was approved by the Research Ethics Committee of the Health Sciences Teaching and Research Foundation - Federal District Health Department (FEPECS/SES-DF). The study was registered in the Brazilian Registry of Clinical Trials (REBEC).

The Informed Consent Form was elaborated according to the norms of the Research Ethics Committee - FEPECS/SES-DF. Researchers maintained secrecy about the mother and infant identity and to use the data solely for scientific purposes.

\section{Design, setting and period}

This is a crossover Randomized Controlled Trial (RCT) conducted at a NICU of a public hospital reference in maternal and child care in Brasilia, Federal District, from September 2015 to March 2016.

\section{Participants}

The participants were preterm infants with corrected gestational age between 32 and 37 weeks; with spontaneous breathing of ambient air; using a heated incubator; weighing between $1,300 \mathrm{~g}$ and 2,000g; with more than 72 hours postpartum; hospitalized for at least 24 hours in the hospital's NICU; and with spontaneous diuresis. We excluded infants who had a bone fracture, due to the positional restrictions of their condition; those who had a history of apnea within 72 hours of data collection, to avoid the possibility of apnea during the research phases; those who underwent painful invasive procedures less than 1 hour before the study intervention, so that residual pain effects did not interfere with the study; and those with central nervous system (CNS) disorders, such as brain hemorrhage, syndromes with neurological impairment, history of seizure, and hypertonia.

The sample calculation was performed in the software Gpower 3.1 , with the following parameters: effect size of $0.25 ; a=0.05$; $\beta=0.80$; number of groups $=2$; number of phases $=6$; correlation between measures of 0.05 . The sample consisted of 20 preterm infants per condition.

\section{Intervention}

The experimental condition was preterm infants placed in a hammock fixed inside the incubator and the control condition 
was preterm infants placed in an O-shaped nest. Nesting and hammock positioning occurred after a stressful stimulus, which was diaper change. In both conditions - nest and hammock - a subscapular cushion was used to provide a slight extension of the neck, preventing upper airway obstruction.

\section{Data collection and measured variables}

After the signing of the Informed Consent Form (TCLE) and the data collection in the medical record, the preterm infant was randomized to their initial condition (nest or hammock). After that, the pulse oximeter (Monitor Portal DX 2020, available in the unit) was placed on the right upper limb. After this, a 5-minute period was respected, without any manipulation of the infant, for their stabilization.

After the five minutes of stabilization, the 6 phases of the research began, which were: Baseline I- 5 minutes before diaper change and positioning of the premature infant in the comfort method (nest and hammock); Baseline II: 1 minute before diaper change and positioning; Procedure: During diaper change and positioning of the baby in the comfort method (nest and hammock); Response (PR): 1 minute after diaper change and positioning in the comfort method; Immediate Recovery (IR): 5 minutes after diaper change and positioning in the comfort method; Late Recovery (LR): 10 minutes after diaper change and positioning in the comfort method.

During these phases the infants were filmed through a SONYDigital Handcam camera, model DVD92, used to capture the babies' behavioral images. The camera was in the hands of a researcher throughout the whole period of data collection, from baseline to late recovery.

The $\mathrm{HR}$ and $\mathrm{SpO}_{2}$ were measured minute by minute by another investigator through the data obtained by pulse oximeter. HR and $\mathrm{SpO}_{2}$ were measured in four phases: Baseline I; Procedure; Immediate Recovery; Late Recovery.

The evaluation of sleep stages and waking patterns occurred in four phases: baseline II; response; immediate recovery and late recovery. The procedure period was excluded because of the difficulty to see the baby's face during the diaper change. Sleep stages and wakefulness were analyzed according to the states defined by Pretchel: deep sleep $=1$, active sleep $=2$, quiet alert $=3$, active alert $=4$, crying $=5^{(18)}$.

However, we opted for grouping the variables deep sleep, active sleep, quiet alert, active alert and crying in two categorical variables: sleep (active sleep and deep sleep) and wakefulness (quiet alert, active alert and crying), according to some studies ${ }^{(12,19)}$.

For the behavioral analysis of the sleep-wake patterns, the encoders received a training titled "Systematic Observation Microanalytical Encoding of Behavioral Variables" promoted by the Neonatal Nursing research group of the School of Nursing of Ribeirão Preto - University of São Paulo (USP). This microanalytical observation is characterized by the continuous observation related to the behavior encoding process, conducted second by second ${ }^{(3-4)}$.

Encoders that achieved a Kappa coefficient of interobserver reliability of at least $80 \%$ in $20 \%$ of the randomly selected sample were considered able ${ }^{(3-4)}$. This interobserver reliability referred to the encoding of a baby's image by two encoders, which should be as similar as possible. During the first evaluation of the Kappa coefficient, two researchers did not reach reliability greater than $80 \%$. Therefore, another training was conducted with the researchers and the final Kappa coefficient was: observer 1X2= $84 \%$; observer $1 \times 3=84 \%$ and observer $2 \times 3=97 \%$.

During the encoding of the images, the software MagixMovie Editor 15 Pro Plus was used to visualize the baby's behavioral signals. This program allows frame-by-frame or slowmotion video mode, providing more detailed visualization of the face and movements of premature infants.

\section{Randomization and blinding}

Preterm infants were allocated in the two conditions - control (nest) and intervention (hammock), and the allocation order in the first day was defined by randomization. Three research assistants prepared the piece of papers and conducted the draw. The infant was allocated in the first condition drawn (nest or hammock), and after a 24-hour "washout" period, was submitted to the other intervention condition (nest or hammock).

Due to the nature of the study interventions, it was not possible for the researchers to remain blind during data collection and image encoding. However, there was blindness in the construction of the database and during the analysis of the data, in which the conditions were named " 1 " and " 2 ".

Four trained researchers participated in the image encoding and the interobserver reliability was set as Kappa greater than $80 \%$ in $20 \%$ of the sample.

\section{Statistical analysis}

The data were typed in a spreadsheet in the software IBM SPSS (version 20.0) and the data consistency was analyzed. The characterization variables of preterm infants and mothers were analyzed using descriptive statistics (mean, standard deviation, frequency).

The normality of the infants' variables was tested using the Kolmogorov-Smirnov test. In the case of normal distribution, the " $t$ " student test was used to compare the quantitative variables of the nest and hammock conditions. For the comparison between the rest and nest conditions of variables without normal distribution, the Mann-Whitney non-parametric test for two independent samples was chosen.

For the behavioral and physiological variables, the Repeated Measures Analysis of Variance (RM-ANOVA) was used. The Tukey and Bonferroni test were used to verify if there were intra-subject differences and differences between the intervention conditions. For the categorical variables, the chi-square or Fisher exact test was used.

\section{RESULTS}

Of the 28 preterm infants who started participating in this study, 8 were excluded: 4 due to the need for oxygen support; 1 was transferred to another hospital during the Washout period; 2 due to technical problems during collection; 1 during video analysis. Therefore, 20 preterm infants completed their participation in the research, according to Figure 1. 


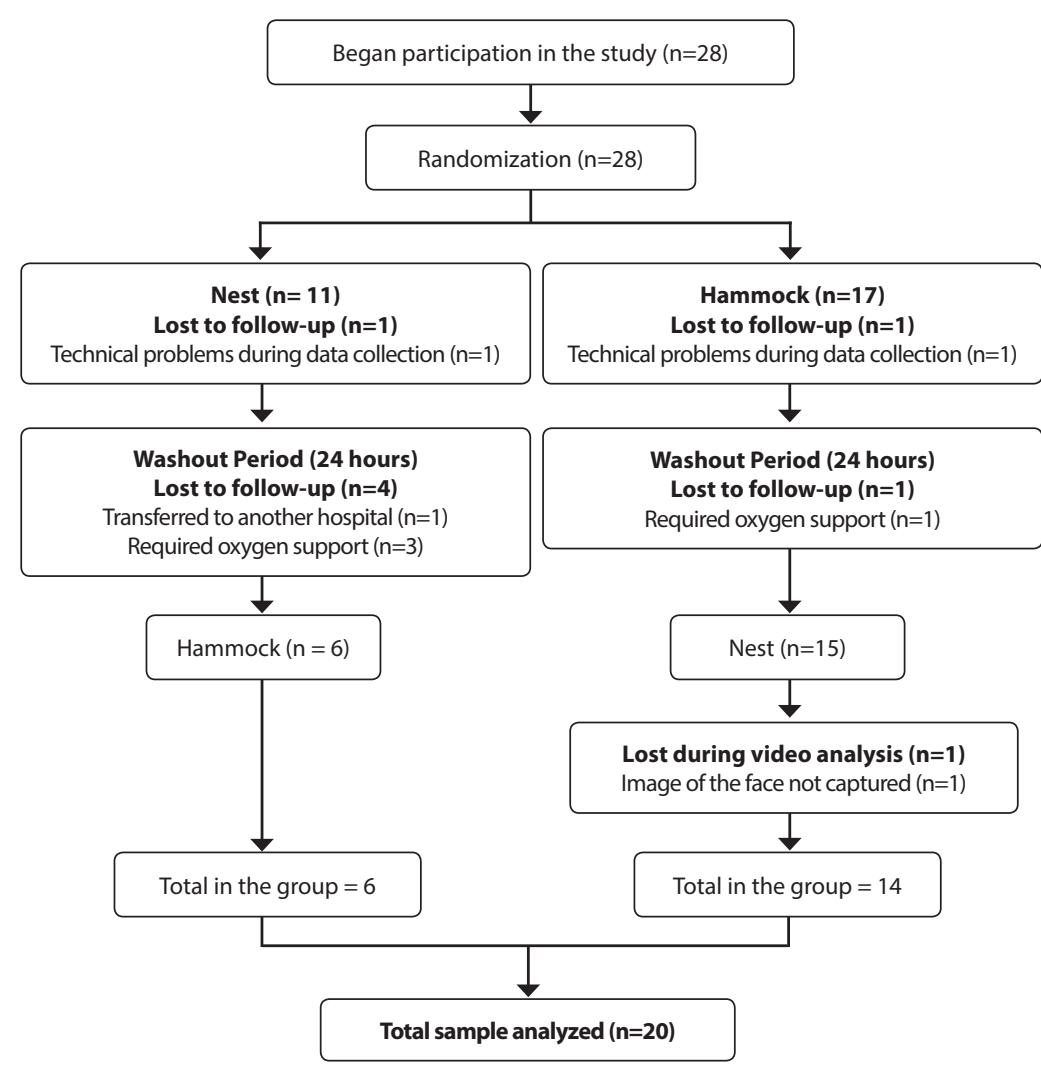

Figure 1 - CONSORT flowchart of the research according to the allocation in the intervention conditions, Brasília, Distrito Federal, Brazil, 2016

The female gender (55.0\%) and cesarean delivery (65\%) were more frequent. At birth, $60 \%$ of the preterm infants had no complications, $30 \%$ required oxygen support and $10 \%$ resuscitation. Regarding the Apgar score, the mean at the $1^{\text {st }}$ minute was 6.60 $( \pm 1.603)$ and at the 5th minute $8.05( \pm 1.432)$.

At birth, the Pls presented a mean weight of $1,390,25 \mathrm{~g}( \pm 381,956)$ and mean gestational age of 220,30 days $( \pm 15,273)$, that is, 31.4 weeks $( \pm 2.17)$. The mean corrected gestational age, on the day of the intervention, was 242.35 ( \pm 11.27 ), corresponding to 34.6 weeks $( \pm 1.6)$. The mean length of hospitalization in the NICU and in the neonatal intermediate care unit was $11.65( \pm 14.012)$ and 8.95 ( \pm 7.097$)$, respectively.

As for the results of the physiological variables measured, the comparison between the mean heart rate (HR) of infants in the nest and infants in the hammock (Table 1) showed no statistically significant difference $(p=0.62)$. The mean heart rate of preterm infants was lower than in the baseline period $(p=0.34)$, the procedure period $(p=0.48)$ and late recovery $(p=0.66)$; however, this difference was not significant. In the immediate recovery period, the mean HR of infants was lower in the hammock than in the nest, but this difference was not significant $(p=0.21)$.

Regarding the comparisons between the collection phases, only for the hammock position (intra-subject analysis), HR was statistically significant between the procedure and immediate recovery phases $(p=0.05)$. This result showed that during diaper change there was an increase in HR compared with the recovery phase, when the baby was already positioned in the hammock. In the comparisons between the other phases, there were no significant differences: baseline and procedure $(p=0.27)$; baseline and immediate recovery $(p=1.00)$; baseline and late recovery $(p=0.55)$; procedure and late recovery $(p=1.00)$; immediate and late recovery $(p=0.15)$.

The comparison of the mean Oxygen Saturation $\left(\mathrm{SpO}_{2}\right)$ of preterm infants when placed in the nest and in the hammock (Table 1) evidenced that, in all phases, the hammock position was related to higher $\mathrm{SpO}_{2}$. However, this difference was not significant in the phases: baseline $(p=0.35)$, procedure $(p=0.35)$, immediate recovery $(p=0.35)$ and late recovery $(p=0.49)$.

The comparison of the infants' $\mathrm{SpO}_{2}$ between the research phases when placed only in the hammock position (intra-subject analysis) showed no statistically significant differences between the phases: baseline and procedure ( $p=0.99)$; baseline and immediate recovery $(p=1.00)$; baseline and late recovery $(p=1.00)$; procedure and immediate recovery $(p=1.00)$; procedure and late recovery $(p=1.00)$; immediate recovery and late recovery $(p=1.00)$. Preterm infants in hammock position did not present significant differences in the comparison between baseline periods and procedure - periods without the use of the hammock.

As for the results of the comparisons with the categorical variable sleep (active sleep and deep sleep), the differences were not statistically significant when comparing the hammock to the nest, according to the research phases: baseline $(p=0.35)$, response $(p=0.81)$, immediate recovery $(p=0.60)$ and late recovery $(p=0.80)$ (Figure 2$)$.

In the analysis between the phases (intra-subject analysis), only for the hammock position that the sleep categorical variable showed significant difference between the phases: baseline and immediate recovery $(p=0.00)$, baseline and late recovery $(p=0.00)$, response and immediate recovery $(p=0.00)$, response and late recovery $(p=0.00)$. There were no significant differences between baseline and response $(p=1.0)$ and between immediate and late recovery $(p=0.99)$. The baby remained sleeping during recovery periods, when already in the hammock.

Table 1 - Mean values and standard deviations of heart rate and oxygen saturation of preterm infants, according to the periods and conditions of allocation, Brasília, Distrito Federal, Brazil, 2016

\begin{tabular}{|c|c|c|c|c|c|c|}
\hline \multirow[t]{2}{*}{ Phases } & \multirow[t]{2}{*}{ Condition } & \multirow[t]{2}{*}{$\mathbf{n}$} & \multicolumn{2}{|c|}{ Heart Rate } & \multicolumn{2}{|c|}{$\begin{array}{l}\text { Oxygen } \\
\text { Saturation }\end{array}$} \\
\hline & & & $\overline{\mathrm{X}}^{*}$ & $\mathrm{DP}^{+}$ & $\overline{\mathrm{X}}^{*}$ & $\mathrm{DP}^{+}$ \\
\hline \multirow[t]{2}{*}{ Baseline I } & Hammock & 20 & 153.50 & 16.675 & 93.05 & 3.137 \\
\hline & Nest & 20 & 151.10 & 32.097 & 92.15 & 5.585 \\
\hline \multirow[t]{2}{*}{ Procedure } & Hammock & 20 & 153.50 & 34.117 & 90.05 & 7.742 \\
\hline & Nest & 20 & 146.20 & 45.571 & 87.65 & 8.381 \\
\hline \multirow[t]{2}{*}{ Immediate Recovery } & Hammock & 20 & 154.20 & 22.156 & 93.05 & 5.145 \\
\hline & Nest & 20 & 155.85 & 17.312 & 92.50 & 5.094 \\
\hline \multirow[t]{2}{*}{ Late Recovery } & Hammock & 20 & 151.10 & 19.526 & 94.50 & 2.982 \\
\hline & Nest & 20 & 143.15 & 37.406 & 90.30 & 7.733 \\
\hline
\end{tabular}

Note: ${ }^{*} \overline{\mathrm{X}}=$ mean, ${ }^{\top} \mathrm{S} D=$ standard deviation 
As for the categorical variable wakefulness (active alert, quiet alert and crying), the comparisons between the nest and hammock showed no statistically significant results in the phases: baseline $(p=0.40)$, response $(p=0.62)$, immediate recovery $(p=0.71)$ and late recovery $(p=0.60)$ (Figure 3$)$.

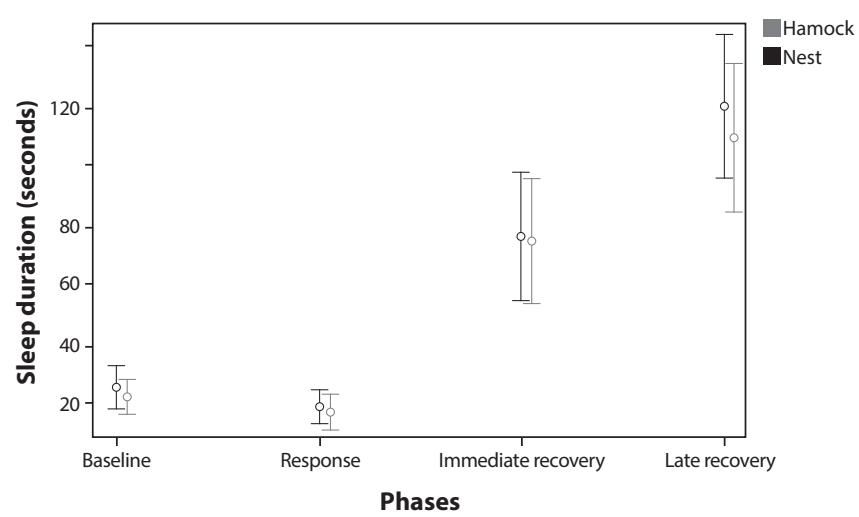

Figure 2 - Mean duration of sleep (deep and active sleep), according to the phases and allocation conditions, Brasília, Distrito Federal, Brazil, 2016

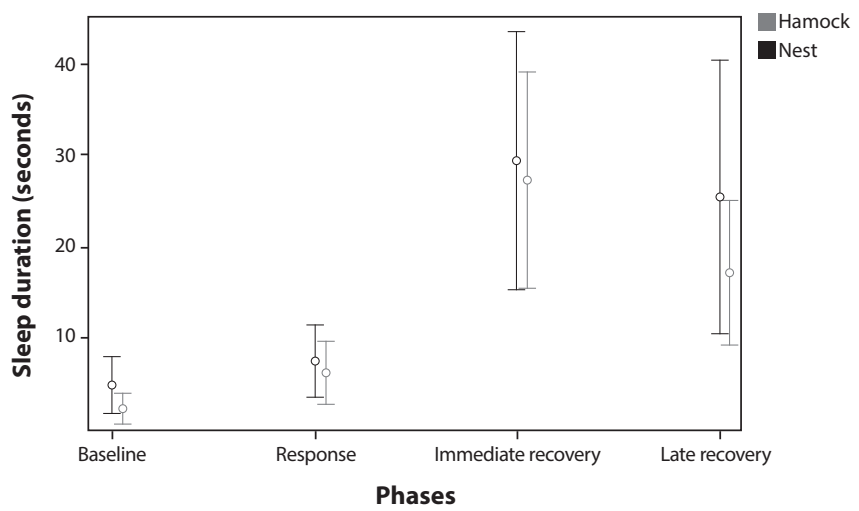

Figure 3 - Mean duration of wakefulness (quiet alert, active alert and crying), according to phases and allocation conditions, Brasília, Distrito Federal, Brazil, 2016

The intra-subject comparison only with the hammock group, according to the different phases of the data collection, showed no significant difference between the phases: baseline and response $(p=1.00)$; baseline and immediate recovery $(p=0.40)$; baseline and late recovery $(p=0.97)$; response and immediate recovery $(p=0.70)$; response and late recovery $(p=0.99)$; immediate recovery and late recovery $(p=1.00)$.

\section{DISCUSSION}

The present study is the first one to investigate the hammock as a comfort measure for preterm infants after diaper change. The main finding of the study was that the use of the hammock after diaper change did not differ from the use of the nest, considering physiological and behavioral variables.

It is possible that stressful but non-nociceptive stimuli, such as routine manipulation during NICU stay, begin to trigger pain responses because the neonatal immature nociceptive system becomes more sensitive after experiencing multiple and repetitive noxious stimuli(i).
Excessive stress in the NICU environment can cause long-term sequelae and make the child more sensitive to pain and stress ${ }^{(7)}$.

As a stress relief measure, there are still few studies that address the hammock as an intervention for stressful and painful procedures. The use of baby hammocks has been studied in relation to motor performance ${ }^{(15,20)}$ and clinical status ${ }^{(13,21-22)}$.

An exploratory and descriptive study aimed to evaluate the clinical status of twelve infants (full-term and preterm) hospitalized in the NICU before and after the use of the hammock. The results of this study showed no differences in $\mathrm{HR}$ and $\mathrm{SpO}_{2}$ with or without the use of the hammock. However, the mean stress score was better with the use of the hammock, with a mean of 9.4 $( \pm 1.1)$ with the hammock vs $7.5( \pm 2.0)$ without $i^{(21)}$. The findings regarding oxygen saturation were similar to those of the present study, which found no statistically significant difference when comparing infants in the hammock or not. However, regarding $H R$, the results were divergent from this study, since HR was statistically significant between the procedure - when the baby was not in the hammock - and the immediate recovery - when the baby was already in the hammock.

Another experimental study compared the prone position in the mattress with the hammock positioning in $15 \mathrm{PIs}$, who remained 20 minutes in each position ${ }^{(22)}$. The results showed a significant reduction in HR after 15 minutes using the hammock, corroborating the results of this study.

A clinical trial investigated if hammock sleep affected oxygenation in young infants ( 4 to 8 weeks of birth) compared with a bassinet, due to the risk of airway compromise due to flexion of the neck. There was no significant difference in mean $\mathrm{SpO} 2$ or rate of oxygen desaturation events between the hammock and the bassinet. The authors concluded that, when correctly used, the hammock sleep position does not compromise the upper airways of infants ${ }^{(13)}$.

Another study, that compared the hammock with the prone position ${ }^{(22)}$, found significantly lower HR $(p=0.04)$ for the hammock group, diverging from the findings of the present study. Other studies ${ }^{(15,21)}$, one comparing the hammock position with the nested prone position and the other comparing positioning with and without the hammock found no differences in HR with or without the hammock ( $p>0.05$, in both), corroborating the findings of this study $(p=0.622)$. However, none of these studies evaluated the effect of using the hammock after a stressful or painful stimulus and the intraphase analyzes.

Sleep evaluation was also conducted in 8-week old infants for $1-3 h^{(13)}$. The results showed that the number of awakenings per hour was similar in the two groups evaluated - hammock and bassinet; there was no significant difference in percentage time in each sleep stage between the hammock and the bassinet; there was an apparent trend to faster sleep onset in the hammock; however, the infants slept less in the hammock. These findings differ from those found in the present study, since the analysis between the phases (intra-subject analysis), only for the hammock condition, showed a significant difference between phases with and without the hammock.

In contrast, studies have also shown nesting as a favoring factor for the baby's sleep when compared to its non-use. Other studies consider it as the gold standard for promoting comfort of hospitalized preterm infants ${ }^{(12,14,19)}$. Therefore, regarding the 
comparison between the hammock and nesting, the results of the present study did not present statistically significant differences in $\mathrm{HR}, \mathrm{SpO}_{2}$, sleep and wakefulness. Thus, the hammock can be a promising and alternative intervention for promoting comfort and sleep of the preterm infant hospitalized in a NICU.

However, further studies with larger samples, evaluating the preterm infant in other situations and for a longer time are still necessary, as it is also necessary to investigate possible adverse effects.

\section{Limitations of the study}

The fact that the evaluators were not blinded to the type of intervention used can be considered as a limitation of the present study. This blinding was not possible due to the nature of the two postural comfort methods.

Another limitation of the study was the fact that the infants did not use the hammock prior to the study, so they were not used to the method. In contrast, the use of the nest is a routine of the unit, and all the babies are nested when hospitalized in the NICU.

\section{Contributions of the study}

This research aims to make an important contribution to clinical practice and to the production of evidence on the use of hammocks, since there are few clinical studies that evaluate its use.
In addition, the research raises greater discussions about the role of nursing in the use of methods that provide comfort to hospitalized infants.

And, more importantly, this research is expected to contribute to improving the quality of life of preterm infants through the inclusion of new interventions that provide comfort and sleep for this patient.

\section{CONCLUSION}

There was no statistically significant difference between the nest and the hammock positions regarding the physiological variables and the sleep state and wakefulness of preterm infants.

However, regarding sleep, the comparison between the data collection phases of preterm infants positioned in hammocks revealed a significant difference between the baseline period (before the use of the hammock) and recovery (in use of the hammock). These findings show that the hammock promoted sleep after a stressful stimulus (diaper change), since there were significant differences between the phases before the intervention and the phases in which the infant was in the hammock.

The baby hammock is a promising intervention; however, new studies on the hammock positioning and its adverse effects are necessary, in order to contribute to the well-being and comfort of the newborn.

\section{REFERENCES}

1. Als H, Duffy FH, McAnulty G, Rivkin MJ, Vajapeyam S, Mulkern RV, et al. NIDCAP improves brain function and structure in preterm infants with severe intrauterine growth restriction. J Perinatol. 2012;32(10):797-803. doi:10.1038/jp.2011.201

2. Westrup B. Family-centered developmentally supportive care: the Swedish example. Arch Pediatr. 2015;22(10):1086-91. doi:10.1016/j. arcped.2015.07.005

3. Castral TC, Warnock F, Santos CB, Daré MF, Moreira AC, Antonini SRR, et al. Maternal mood and concordant maternal and infant salivary cortisol during heel lance while in kangaroo care. Eur J Pain. 2015;19(3):429-38. doi: 10.1002/ejp.566

4. Ribeiro LM, Castral TC, Montanholi LL, Dare M F, de Araujo Silva AC, Antonini SRR, et al. Human milk for neonatal pain relief during ophtalmoscopy. Rev Esc Enferm USP. 2013;47(5):1039-45. doi: 10.1590/S0080-623420130000500005

5. Gokulu G, Bilgen H, Ozdemir H, Sarıoz A, Memisoglu A, Gucuyener K, et al. Comparative heel stick study showed that newborn infants who had undergone repeated painful procedures showed increased short-term pain responses. Acta Paediatr. 2016;105(11):e520-5. doi: 10.1111/apa.13557

6. Rodrigues AC, Guinsburg R. Pain evaluation after a non-nociceptive stimulus in preterm infants during the first 28 days of life. Early Hum Dev. 2013;89(2):75-9. doi: 10.1016/j.earlhumdev.2012.08.002

7. Lyngstad LT, Tandberg BS, Storm H, Ekeberg BL, Moen A. Does skin-to-skin contact reduce stress during diaper change in preterm infants? Early Hum Dev. 2014;90(4):169-72. doi: 10.1016/j.earlhumdev.2014.01.011

8. Mörelius E, Hellström-Westas L, Carlén C, Norman E, Nelson N. Is a nappy change stressful to neonates? Early Hum Dev. 2006;82(10):669-76. doi: 10.1016/j.earlhumdev.2005.12.013

9. Madlinger-Lewis L, Reynolds L, Zarem C, Crapnell T, Inder T, Pineda R. The effects of alternative positioning on preterm infants in the neonatal intensive care unit: a randomized clinical trial. Res Dev Disabil. 2014;35(2):490-7. doi: 10.1016/j.ridd.2013.11.019

10. Cabral TI, Silva LGP, Tudella E, Martinez CMS. Motor development and sensory processing: A comparative study between preterm and term infants. Res Dev Disabil. 2015;36C:102-7. doi: 10.1016/j.ridd.2014.09.018

11. Comaru T, Miura E. Postural support improves distress and pain during diaper change in preterm infants. J Perinatol. 2009;29(7):504-7. doi: 10.1038/jp.2009.13

12. Visscher MO, Lacina L, Casper T, Dixon M, Harmeyer J, Haberman B, et al. Conformational positioning improves sleep in premature infants with feeding difficulties. J Pediatr. 2015;166(1):44-8. doi: 10.1016/j.jpeds.2014.09.012

13. Chiu K, Tonkin SL, Gunn AJ, McIntosh CC. Are baby hammocks safe for sleeping babies? A randomised controlled trial. Acta Paediatr. 2014;103(7):783-7. doi: 10.1111/apa.12663 
14. Poulose R, Babu M, Rastogi S. Effect of Nesting on Posture Discomfort and Physiological Parameters of Low Birth Weight Infants. IOSR J Nurs Health Sci. 2015;4(1):46-50. doi: 10.9790/1959-04114650

15. Keller A, Arbel N, Merlob P, Davidson S. Neurobehavioral and autonomic effects of hammock positioning in infants with very low birth weight. Pediatr Phys Ther. 2003;15(1):3-7. doi: 10.1097/01.PEP.0000049507.48347.26

16. Bottos M, Pettenazzo A, Giancola G, Stefani D, Pettena G, Viscolani B, et al. The effect of a 'containing' position in a hammock versus the supine position on the cutaneous oxygen level in premature and term babies. Early Hum Dev. 1985;1 1(3-4):265-73. doi: 10.1016/0378-3782(85)90080-5

17. Cavalaria SVF. A terapia ocupacional utilizando redinhas no atendimento de recém-nascidos na uti-neonatal [Internet]. Unisalesiano. 2009 [cited 2015 Jul 15]. Available from: http://www.unisalesiano.edu.br/encontro2009/trabalho/aceitos/PO17034896836.pdf

18. Pretchtl H. The behavioural states of the newborn infant (a review). Brain Res. 1974;76(2):185-212. doi: 10.1016/0006-8993(74)90454-5

19. Kihara $\mathrm{H}$, Nakamura T. Nested and swaddled positioning support in the prone position facilitates sleep and heart rate stability in very low birth weight infants. Res Rep Neonatol. 2013;3:11-4. doi: 10.2147/RRN.S41292

20. Fernandes PTS. Influence of the Hammock positioning in the neuromotor development of pre-term newborn babies [dissertação] [Internet]. Uberaba: Universidade Federal do Triângulo Mineiro; 2011 [cited 2016 Aug 10]. Available from: http://bdtd.uftm.edu.br/handle/tede/157

21. Lino LH, Coelho PG, Fonseca FLA, Filipini R. The swing balance benefits in incubators with newborns on neonatal ITU: the humanization strategy. Enferm Rev [Internet]. 2015 [cited 2016 Aug 10];18(1):88-100. Available from: http://200.229.32.55/index.php/enfermagemrevista/ article/view/9372

22. Costa DG, Morais LBA, Nascimento IM. Comparative study of oxygen saturation, heart rate, respiratory rate of preterm neonates positioned in Hammock and ventral decubitus. Braz J Phys Ther. 2004;8(1):53-53. 